\title{
Uterine rupture in a primigravid patient, an uncommon but severe obstetrical event: a case report
}

\author{
Lotte Posthumus ${ }^{1}$ and Marielle Eveline Donker ${ }^{2^{*}}$
}

\begin{abstract}
Background: A spontaneous rupture of the unscarred uterus in a primigravid patient is extremely rare and is associated with high perinatal and maternal morbidity and mortality.

Case presentation: A 34-year-old white primigravid woman, $31+3$ weeks of gestation, presented with pre-eclampsia and developed a sudden acute abdomen. An emergency laparotomy was performed and a uterine rupture was found as the cause of the event. A stillborn girl was born.
\end{abstract}

Conclusion: A rupture of the pregnant uterus should always be considered in a pregnant woman presenting with abdominal pain, even in a primigravid patient.

Keywords: Uterine rupture, Primigravid, Unscarred uterus, Acute abdomen

\section{Background}

Rupture of the pregnant uterus is an uncommon but severe obstetrical event, which is associated with high perinatal and maternal morbidity and mortality $[1,2]$. It occurs mostly secondary to a previous caesarean section (the "scarred uterus"), making this its main risk factor $[1,2]$ with an incidence of around $1 \%[1]$. The estimated incidence of a rupture of the unscarred uterus is $1 / 8000$ to 15,000 deliveries $[3,4]$ or, as investigated by the World Health Organization (WHO), 0.006\% [1]. Rupture in a primigravid patient is extremely rare and in most cases totally unexpected. The incidence of uterus rupture in general (primigravid or multigravid) is significantly higher in developing countries than in developed countries [1] caused by worse antenatal and obstetric care (such as periodic ultrasounds detecting for abnormalities and in-time cesarean section in case of prolonged or obstructed labor) [5], high frequency of home deliveries with prolonged labor, and grand multiparity $[1,5]$. Until now there have only been 11 cases of a spontaneous rupture, without any risk factors [6-16],

\footnotetext{
* Correspondence: M.E.Donker@amc.uva.nl

${ }^{2}$ Academisch Medisch Centrum, Meibergdreef 9, 1105 AZ Amsterdam, The Netherlands

Full list of author information is available at the end of the article
}

described in the English literature. Five of these cases were primigravid patients.

Here we report another case of a spontaneous rupture of an unscarred uterus in a primigravid patient, without any previous risk factors, at $31+3$ weeks of gestation.

\section{Case presentation}

A healthy 34-year-old white primigravid woman presented at $28+4$ weeks of gestation with mild preeclampsia. She had no significant past medical history and her antenatal care had been uneventful. The preeclampsia was treated with intravenously administered magnesium sulfate (at admission) and methyldopa 750 mg 3 times daily and she received corticosteroids for accelerating fetal lung maturation. An ultrasound showed an intrauterine growth-restricted child in head position with an estimated fetal weight of 1047 gr and oligohydramnios. During admission, our patient was clinically and biochemically stable and daily cardiotocograms showed a reassuring fetal heart rate pattern. Two weeks after admission $(30+4$ weeks), the estimated weight of the fetus was 1116 gr with normal umbilical artery Doppler screening.

At gestational age of $31+3$ weeks, almost 2 weeks after admission, our patient complained about sudden lower abdominal pain and fever. There were no previous 
signs of preterm labor before this acute presentation. On clinical examination she looked pale with a blood pressure of 145/75 mmHg, a pulse of 103 beats per minute (bpm), a temperature of $37.9{ }^{\circ} \mathrm{C}$, and a normal respiratory rate. On first physical examination her abdomen was soft but with slight tenderness in the lower abdomen. Ultrasonic evaluation showed an unviable fetus with no obvious signs of an abruption of the placenta. A vaginal examination revealed a closed portio and no vaginal bleeding. During the evaluation, she deteriorated with a blood pressure of $63 / 33 \mathrm{mmHg}$ and a pulse of $130 \mathrm{bpm}$. She complained about an increased fluctuating abdominal pain and shoulder pain and showed difficulty in breathing. Her hypotension was considered due to intrauterine blood loss. Despite adequate fluid resuscitation, she remained hemodynamically unstable. She developed an acute abdomen. Ultrasound was repeated and showed free abdominal fluid. An emergency median laparotomy was performed and a hemoperitoneum of approximately 3 liters of blood was recovered. Both placenta and fetus were found outside the uterus due to a uterus rupture (Fig. 1). The tear was $5 \mathrm{~cm}$ long and located in fundo close to the insertion of the left tube. A stillborn girl with a weight of 1130 grams was born. Our patient's uterus was closed in two layers. Blood and clots were removed. Our patient's pelvis showed no abnormalities, especially no evidence of endometriosis or adhesions. Inspection of her liver showed no rupture. The placenta was sent for pathological examination. Syntocinon (oxytocin) was administered intravenously. There was an estimated total blood loss of 3500 cc. Six units of blood and 2 units of blood plasma were transfused.

In the days after surgery she developed an ileus, which was treated conservatively and she developed high fever with increased infectious parameters, due to small abscesses dorsal of her uterus, treated with antibiotics. A

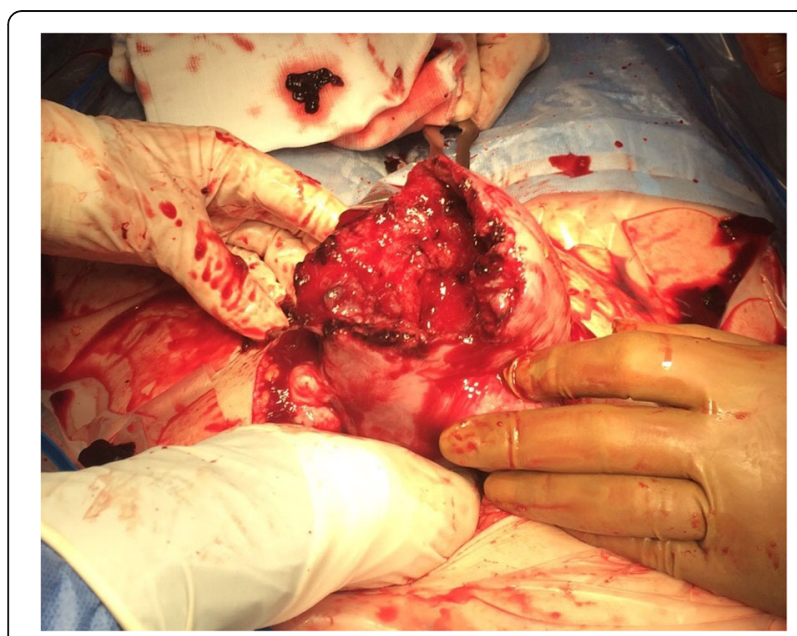

Fig. 1 Rupture in the fundus of the uterus computed tomography (CT) scan showed a subcapsular liver hematoma without a decrease in her hemoglobin level or platelets level, which was treated conservatively. Blood cultures showed a Staphylococcus aureus infection. Endocarditis was excluded. An electrocardiogram (ECG) showed an intermittent second-grade atrioventricular (AV) block-type Wenckebach, without clinical consequence. The $S$. aureus infection was most likely a cause of an infected wound, which was treated with intravenously administered antibiotics, with a good response. One month after the event she was sent home. She was strongly advised not to get pregnant again. In the case of a new pregnancy, careful monitoring and an elective cesarean section were advised.

\section{Discussion and conclusions}

Rupture of the non-laboring uterus is rare and can be life-threatening for the mother and fetus. Two reports $[17,18]$ on primigravid uterine rupture together show no uterine rupture among 52,876 primigravid deliveries over 10 and 13 years' time. In developed countries the prevalence of uterine rupture in pregnant women with previous cesarean section has been reported to be approximately $1 \%$ whereas it is extremely rare in women without a history of cesarean section [1]. To the best of our knowledge, this is the sixth documented rupture of a primigravid uterus occurring before onset of labor without previous risk factors. All cases, except for one [12], were associated with symptoms of acute abdomen with prominent hemoperitoneum, occurring primarily in the third trimester. Four fetuses died before delivery, however, all patients recovered following adequate treatment [6-16]. The most common rupture sites were the cornual area and the uterine fundus. In our case, review of the first trimester ultrasound scans was unhelpful to assess the location of pregnancy. During surgery the tear in our patient's uterus was close to the insertion of the left tube. This could have indicated a cornual or angular pregnancy, but first trimester ultrasound scans showed a normal location of pregnancy and the gestational growth was towards the uterine cavity. Furthermore, there was no (painful) asymmetrical enlargement of her uterus or abdomen with physical examination. Therefore, a cornual or angular pregnancy is considered not to be likely in this case.

The pathogenesis of rupture of the unscarred uterus is not well known. Associated factors are trauma (for example, domestic violence, traffic accident) and obstetric maneuvers (for example, internal version, breech extraction) which were not presented in this case. Medical induction or augmentation (oxytocin stimulation) of labor causes iatrogenic risk for rupture of the uterus [2, 19]. Other factors include other intrauterine surgeries, uterine anomalies [20-22], grand multiparity [2, 19, 23], abnormal 
placentation [22, 24], macrosomia [2], in utero exposure to diethylstilbestrol [25], cocaine abuse [26, 27], prolonged labor [2], and obstructed labor [7]. However, none of these factors were found in our patient. Ehlers-Danlos type IV has also been related to uterine rupture [28-30], but was excluded in our patient by genetic testing. In a review by Uccella et al. [31], 24 cases of prelabor uterine rupture in a primigravida were analyzed over the previous 60 years. Of 23 cases in which specific clinical data were available, 16 cases had a history of previous uterine surgery or instrumentation. Other identified risk factors included the ones mentioned above. Only one case had no clear risk factor [31].

During pregnancy, physiologic and anatomic changes may affect the presentation of abdominal pain [32-36]. Symptoms of normal pregnancy (nausea, vomiting, abdominal pain) could mimic severe abdominal pathology and fever is not always present [33-36]. Therefore, an acute abdomen during pregnancy often presents atypically and it could be difficult to distinguish a tense abdomen from a normal pregnancy $[32,37]$ and to detect an acute abdomen based on clinical and physical examination only [38].

Because of the rare incidence and the aspecific presentation, rupture of the uterus in our case was not the primary diagnosis. In combination with the pre-eclampsia, abdominal pain, tender lower abdomen, and negative heartbeat of the fetus, we thought of an abruptio placentae. It is unclear if the acute presentation was only due to the uterus rupture, or if this abruptio occurred prior to the rupture, making it a possible cause of the event [39]. Mourad et al. [14] recently also suggested that given the rarity of an idiopathic spontaneous uterine rupture in an unscarred primigravid uterus, a placental abruption is a more likely cause of a uterine rupture, especially in patients with preeclampsia [40]. In our case, pathological examination of the placenta showed signs of abruption and, therefore, in combination with the possible cornual or angular localization of the pregnancy, could be the cause of this severe obstetrical complication.

Rupture of the pregnant uterus is an uncommon but severe obstetrical event, which is associated with high perinatal and maternal morbidity and mortality $[1,2]$. It often presents atypically, which makes it difficult to detect based on clinical and physical examination only. The main risk factor is a previous caesarean section (the "scarred uterus"), but a rupture of the pregnant uterus should always be considered in a pregnant woman presenting with abdominal pain, even in a primigravid patient.

\section{Acknowledgements}

Not applicable.

Funding

Not applicable.
Availability of data and materials

Not applicable.

\section{Authors' contributions}

Equal contribution to the article of LP and MED. Both authors read and approved the final manuscript.

Ethics approval and consent to participate

Not applicable.

\section{Consent for publication}

Written informed consent was obtained from the patient for publication of this case report and any accompanying images. A copy of the written consent is available for review by the Editor-in-Chief of this journal.

\section{Competing interests}

The authors declare that they have no competing interests.

\section{Publisher's Note}

Springer Nature remains neutral with regard to jurisdictional claims in published maps and institutional affiliations.

\section{Author details}

${ }^{1}$ Spaarne Gasthuis, Spaarnepoort 1, 2134 TM Hoofddorp, The Netherlands. ${ }^{2}$ Academisch Medisch Centrum, Meibergdreef 9, 1105 AZ Amsterdam, The Netherlands.

Received: 17 May 2017 Accepted: 6 November 2017 Published online: 06 December 2017

\section{References}

1. Hofmeyr GJ, Say L, Gulmezoglu AM. WHO systematic review of maternal mortality and morbidity: The prevalence of uterine rupture. BJOG. 2005; 112(9):1221-8

2. Saglamtas M, Vicdan K, Yalcin H, Yilmaz Z, Yesilyurt H, Gokmen O. Rupture of the uterus. Int J Gynaecol Obstet. 1995;49(1):9-15.

3. Miller DA, Goodwin TM, Gherman RB, Paul RH. Intrapartum rupture of the unscarred uterus. Obstet Gynecol. 1997;89(5 Pt 1):671-3.

4. Sweeten KM, Graves WK, Athanassiou A. Spontaneous rupture of the unscarred uterus. Am J Obstet Gynecol. 1995;172(6):1851-5. discussion 1855-6.

5. Konje JC, Odukoya OA, Ladipo OA. Ruptured uterus in Ibadan - a twelve year review. Int J Gynaecol Obstet. 1990;32(3):207-13.

6. Abbi M, Misra R. Rupture of uterus in a primigravida prior to onset of labor. Int J Fertil Womens Med. 1997;42(6):418-20.

7. Langton J, Fishwick K, Kumar B, Nwosu EC. Spontaneous rupture of an unscarred gravid uterus at 32 weeks gestation. Hum Reprod. 1997;12(9): 2066-7

8. Wang PH, Chao HT, Too LL, Yuan CC. Primary repair of cornual rupture occurring at 21 weeks gestation and successful pregnancy outcome. Hum Reprod. 1999;14(7):1894-5.

9. Rana R, Puri M. Pre-labor silent rupture of unscarred uterus at 32 weeks with intact amniotic sac extrusion: A case report. Cases J. 2009;2:7095.

10. Silva G, Gange P, Karunarathne N, Senevirathne N. Spontaneous rupture of an unscarred non-labouring gravid uterus at 32 weeks gestation. Sri Lanka J Obstet Gynaecol. 2012;34(2):53-4.

11. Sun HD, Su WH, Chang WH, Wen L, Huang BS, Wang PH. Rupture of a pregnant unscarred uterus in an early secondary trimester: A case report and brief review. J Obstet Gynaecol Res. 2012;38(2):442-5.

12. Mizutamari $\mathrm{E}_{1}$ Honda $\mathrm{T}$, Ohba $\mathrm{T}$, Katabuchi $\mathrm{H}$. Spontaneous rupture of an unscarred gravid uterus in a primigravid woman at 32 weeks of gestation. Case Rep Obstet Gynecol. 2014;2014:209585.

13. Mannini L, Sorbi F, Ghizzoni V, Masini G, Fambrini M, Noci I. Spontaneous unscarred uterine rupture at 15 weeks of pregnancy: A case report. Ochsner J. 2016:16(4):545-7.

14. Mourad WS, Bersano DJ, Greenspan PB, Harper DM. Spontaneous rupture of unscarred uterus in a primigravida with preterm prelabour rupture of membranes. BMJ Case Rep. 2015;2015. doi:10.1136/bcr-2014-207321

15. Abdalla N, Reinholz-Jaskolska M, Bachanek M, Cendrowski K, Stanczak R, Sawicki W. Hemoperitoneum in a patient with spontaneous rupture of the 
posterior wall of an unscarred uterus in the second trimester of pregnancy. BMC Res Notes. 2015;8:603.

16. Nielsen SK, Hoj L. Asymptomatic spontaneous rupture of the uterus without previous sectio. Ugeskr Laeger. 2017;179(9): pii V09160630

17. Gardeil F, Daly S, Turner MJ. Uterine rupture in pregnancy reviewed. Eur J Obstet Gynecol Reprod Biol. 1994;56(2):107-10.

18. Cahill DJ, Boylan PC, O'Herlihy C. Does oxytocin augmentation increase perinatal risk in primigravid labor? Am J Obstet Gynecol. 1992;166(3):847-50.

19. Catanzarite V, Cousins L, Dowling D, Daneshmand S. Oxytocin-associated rupture of an unscarred uterus in a primigravida. Obstet Gynecol. 2006; 108(3 Pt 2):723-5.

20. Jones $D E$, Mitler LK. Rupture of a gravid bicornuate uterus in a primigravida associated with clostridial and bacteroides infection. J Reprod Med. 1978;21(3):185-8.

21. Nahum GG. Uterine anomalies. How common are they, and what is their distribution among subtypes? J Reprod Med. 1998;43(10):877-87.

22. Walsh CA, Baxi LV. Rupture of the primigravid uterus: A review of the literature. Obstet Gynecol Surv. 2007;62(5):327-34. quiz 353-4.

23. Henderson $C E$, Hana RG, Woroch R, Reilly KD. Short interpregnancy interval and misoprostol as additive risks for uterine rupture: A case report. J Reprod Med. 2010;55(7-8):362-4.

24. LeMaire WJ, Louisy C, Dalessandri K, Muschenheim F. Placenta percreta with spontaneous rupture of an unscarred uterus in the second trimester. Obstet Gynecol. 2001;98(5 Pt 2):927-9.

25. Porcu G, Courbiere B, Sakr R, Carcopino X, Gamerre M. Spontaneous rupture of a first-trimester gravid uterus in a woman exposed to diethylstilbestrol in utero. A case report. J Reprod Med. 2003;48(9):744-6.

26. Mishra A, Landzberg BR, Parente JT. Uterine rupture in association with alkaloidal ("crack") cocaine abuse. Am J Obstet Gynecol. 1995;173(1):243-4.

27. Agarwal R, Gupta B, Radhakrishnan G. Rupture of intrapartum unscarred uterus at the fundus: A complication of passive cocaine abuse? Arch Gynecol Obstet. 2011;283 Suppl 1:53-4.

28. Walsh CA, O'Sullivan RJ, Foley ME. Unexplained prelabor uterine rupture in a term primigravida. Obstet Gynecol. 2006;108(3 Pt 2):725-7.

29. Walsh CA, Reardon W, Foley ME. Unexplained prelabor uterine rupture in a term primigravida. Obstet Gynecol. 2007;109(2 Pt 1):455.

30. Pepin M, Schwarze U, Superti-Furga A, Byers PH. Clinical and genetic features of Ehlers-Danlos syndrome type IV, the vascular type. N Engl J Med. 2000;342(10):673-80.

31. Uccella S, Cromi A, Bogani G, Zaffaroni E, Ghezzi F. Spontaneous prelabor uterine rupture in a primigravida: A case report and review of the literature. Am J Obstet Gynecol. 2011;205(5):e6-8.

32. Cappell MS, Friedel D. Abdominal pain during pregnancy. Gastroenterol Clin North Am. 2003;32(1):1-58.

33. Sharp HT. Gastrointestinal surgical conditions during pregnancy. Clin Obstet Gynecol. 1994;37(2):306-15.

34. Kilpatrick CC, Monga M. Approach to the acute abdomen in pregnancy. Obstet Gynecol Clin North Am. 2007:34(3):389-402.

35. Kilpatrick CC, Orejuela FJ. Management of the acute abdomen in pregnancy: A review. Curr Opin Obstet Gynecol. 2008:20(6):534-9.

36. Augustin G, Majerovic M. Non-obstetrical acute abdomen during pregnancy. Eur J Obstet Gynecol Reprod Biol. 2007;131(1):4-12.

37. Sharp HT. The acute abdomen during pregnancy. Clin Obstet Gynecol. 2002;45(2):405-13.

38. Masselli G, Derchi L, McHugo J, et al. Acute abdominal and pelvic pain in pregnancy: ESUR recommendations. Eur Radiol. 2013;23(12):3485-500.

39. Semchyshyn S, Gerulath AH, Strickler RC. Infant survival following uterine rupture and complete abruptio placentae. Obstet Gynecol. 1977;50(1 Suppl):74s-5.

40. Francois KE, Foley MR. Antepartum and postpartum hemorrhage. In: Gabbe SG, Niebyl JR, Simpson JL, editors. Obstetrics: Normal and Problem Pregnancies. 5th ed. Philadelphia: Elsevier Churchill Livingstone; 2007.

\section{Submit your next manuscript to BioMed Central and we will help you at every step:}

- We accept pre-submission inquiries

- Our selector tool helps you to find the most relevant journal

- We provide round the clock customer support

- Convenient online submission

- Thorough peer review

- Inclusion in PubMed and all major indexing services

- Maximum visibility for your research

Submit your manuscript at www.biomedcentral.com/submit
Biomed Central 